\title{
Conflicto Psicosocial Jurídico entre Fundación Instituto de la Mujer y tienda FES por Contenido de Anuncio Publicitario*
}

\section{Conflict Psychosocial Juridic between Foundation Institute of Woman and FES shop for Advertising Content}

\author{
Cristián Venegas Ahumada' \\ Universidad Santo Tomás de Chile
}

(Recepción: Abril 2006 - Aceptación: Agosto 2006)

\begin{abstract}
El objetivo es diagnosticar, con una perspectiva de género, el conflicto psicosocial jurídico, que sucede en Chile, entre Fundación Instituto de la Mujer; y la tienda de ropa juvenil FES, por el anuncio publicitario con contenido de violencia. Se usó un análisis crítico de discurso con matrices para diagnosticar un conflicto, aplicadas al Dictamen Ético del Consejo Nacional de Autorregulación y Ética Publicitaria y al Recurso de Protección interpuesto por la Fundación Instituto de la Mujer: Las matrices diagnostican un conflicto en la interpretación del Art. $3^{\circ}$ del Código Chileno de Ética Publicitaria. Los discursos tienen condiciones de producción (cultura patriarcal, muerte de mujeres víctimas de violencia, la Constitución, las leyes y Convenciones que protegen a la Mujer), para el conflicto, significado como un problema social con victimización colectiva primaria y secundaria de la Mujer.
\end{abstract}

Palabras claves: Conflicto, Análisis Crítico de Discurso, victimización coḷectiva de la Mujer.

The objective is to diagnose, with gender perspective, the conflict psychosocial juridic, happen in Chile, between Foundation Institute of Woman and FES youthful shop for advertising content of violence. To used discourse analysis critic with categories included in matrices for conflict diagnostic, to apply an Ethic Report of the National Council of Auto Regulation and Advertising Ethic and a Protection Appeal of Foundation Institute of Women. The matrices diagnostic conflict about interpretation of the art. $3^{\circ}$ Chilean Code of Advertising Ethic. The discourses have conditions of production (patriarchal culture, woman's dead victims of violence, Constitution, Chilean Code of Advertising Ethic and Conventions for Woman Protection) for the conflict, meaning as social problem with collective victimization primary and secondary of Woman.

Key words: Conflict, Discourse Analysis Critic, collective victimization of Woman.

\section{Introducción}

El objetivo es diagnosticar, con una perspectiva de género (Servicio Nacional de la Mujer, [SERNAM], 2006) el conflicto psicosocial jurídico, que sucede en Chile, entre Fundación Instituto de la Mujer; y la tienda de ropa juvenil $F E S$, por el anuncio ${ }^{2}$ publicitario con contenido de violencia. Los hechos se desarrollaron de la siguiente manera: FES como parte de su cam-

\footnotetext{
- Se agradece a Rosario Larrain, Asistente General del Conscjo Nacional de Autorregulación y Ética Publicitaria [CONAR]; y a Carmen Torres, Directora Ejecutiva de la Fundación Instituto de la Mujer, quienes han tenido la gentileza de enviar el Fallo y el Recurso de Protección, respectivamente, textos indispensables para la presente investigación.

1 Correspondencia a: Cristián Venegas Ahumada. E mail: cristianvenegasahumada@yahoo.cs

2 Sc entenderá como: "mensaje específico que una organización coloca para persuadir a la audiencia" (Allen, O’Guinn, Semenik, 1998, p. 576).
}

paña publicitaria ${ }^{3}$ (Otoño-Invierno) exhibió anuncios con fotografías donde aparecen hombres y mujeres con huellas de agresiones en sus cuerpos $^{4}$. Esto motivó a Marcela Ballara, en su condición de persona natural, y a la Fundación Instituto de la Mujer, en su condición de persona jurídica, a denunciar la situación al Consejo Nacional de Autorregulación y Ética Publicitaria [CONAR], el 13/04/2005, organismo que elabora un Dictamen Ético el 25/04/2005 mediante el cual acoge la denuncia, y sugiere el retiro del anuncio publicitario (CONAR, 2005). El dictamen no es acatado por FES. Así se abre una segunda fase del conflicto donde la Fundación Instituto de la Mujer presenta ante la Corte de Apelaciones de Santiago un Recurso de Protección el 19/05/05 (Lechuga, 2005).

\footnotetext{
3 Conceptualmente, es una "seric de anuncios coordinados y otros esfuerzos de promoción que transmiten un solo tema o idea" (Allen, O'Guinn, Semenik, 1998, p. 578).

4 Ver "Anexo: Ejemplo de Anuncio Publicitario de (FES, 2005)".
} 
$\mathrm{El}$ análisis de discurso es situado en el marco de Condiciones de Producción (Cultura Patriarcal, muerte de mujeres víctimas de violencia, la Constitución, las leyes, el Código Chileno de Ética Publicitaria y las Convenciones que protegen a la Mujer), que permiten dotar de sentido la interacción social discursiva entre actrices / actores que se mencionan al describir el conflicto. Además las Condiciones de Reconocimiento están dadas por la presentación de un Recurso de Protección por parte de FES. Se verá que respecto del Objeto: Contenido del Anuncio Publicitario se construyen connotaciones semióticas distintas según el discurso de las partes involucradas: Violencia / Ficción.

Por tanto el planteamiento del problema puede definirse así: ¿Cómo es el Conflicto psicosocial jurídico entre Fundación Instituto de la Mujer y la tienda FES por el Objeto: Contenido del anuncio publicitario, desde una perspectiva de género?

\section{Antecedentes Teóricos}

\section{Psicología Social Juridica del Discurso en sus Condiciones de Producción. Fundamentos para una Teoría del Conflicto}

El discurso puede definirse como "[...] un principio dialéctico y generativo a la vez, que remite a una red de relaciones de poder que son histórica y culturalmente específicas, construidas $\mathrm{y}$, en consecuencia, susceptibles de cambio. Su status no es, por ello, inmanente sino fundamentalmente político" (Colaizzi, 1990, p. 20). Por tanto la perspectiva que se asume es de género, el cual puede ser definido (según SERNAM, 2006) como:

"Conjunto de pautas de conducta o patrones de relaciones asignados a cada sexo en las diferentes culturas. Se utiliza para demarcar las diferencias socioculturales que existen entre hombres y mujeres y que son impuestas por el sistema de organización política, económica, cultural y social, y por lo tanto, son modificables" (Glosario de conceptos de violencia, 1).

Así entendida, la relación entre hombres y mujeres, puede estudiarse a partir del nexo entre el orden socio-histórico cultural y la subjetividad, donde se da un determinado orden a través de las prácticas (De Quiroga, 2002) discursivas ${ }^{5}$, en este caso, contenidas en el Dictamen Ético del CONAR y el Recurso de Protección interpuesto por Fundación Instituto de la Mujer, los cuales dan forma al conflicto psicosocial jurídico.

Una sociedad Patriarcal como la nuestra no permite el desarrollo pleno de las mujeres, pues está fundamentada en "[...] la violencia para lograr el control social y [produce] tensiones crónicamente engendradas por el modelo dominador / dominado de las relaciones humanas en que se basa" (Eisler, 1987). En una sociedad como esta, las mujeres han sido históricamente postergadas, por eso es necesario hablar de una nueva Victimología cuyo objetivo sea el estudio victimización colectiva, de los temores sentidos de un grupo social a la victimización (Chávez, 2006), en este caso de las Mujeres en el seno de una sociedad Patriarcal que victimiza a través de variadas prácticas, entre las cuales se encuentran algunas formas de publicidad y el comportamiento del aparato jurídico, manifestándose en sus respectivos discursos.

Las formas de victimización son las siguientes: victimización primaria, es la experiencia individual-colectiva de la víctima como efecto directo del delito, materializándose en consecuencias perjudiciales en el ámbito físico, económico, psicológico y/o social. La victimización secundaria es producida por la relación de la víctima individual y socialmente entendida con el sistema jurídico, produciéndose un incremento del daño psicológico y social de la víctima en el contacto con el sistema de administración de justicia, sufriendo, por ejemplo, incomprensiones derivadas de la excesiva burocratización que dilata el tiempo de la respuesta judicial (por una serie de causas organizacionales que no son objeto del presente análisis). Esta forma de victimización es aún más perjudicial que la primaria, porque es el propio sistema jurídico que victimiza a quien le solicita justicia y protección. Como consecuencia de todo esto, el Sistema Judicial, sin proponérselo conscientemente, promueve una percepción negativa de la víctima y del colectivo social del cual forma parte (Chávez, 2006), debilitando la confianza ciudadana en el Sistema Judicial.

\footnotetext{
3 Sin perjuicio de lo anterior, todo el orden social no se reproduce sólo por prácticas discursivas, tal es el caso de la Economía y la distribución del ingreso, por nombrar sólo algunas. Por tanto no se pretende un reduccionismo discursivo.
} 
En una sociedad patriarcal el conflicto entre hombres y mujeres debe ser comprendido mediante una teoría que permita reflexionar sobre la razón de la violencia desde la víctima, no desde el victimario. Se debe escuchar la voz de las víctimas y su discurso. Ha de ser oído para que forme parte de nuestra historia (Díaz, 2006). Así se irá construyendo un futuro sobre la base de una verdad histórica. La teoría que ayudará en este sentido es la perspectiva de género, la cual se construye sobre la base de la memoria histórica de las mujeres, para así no negar el pasado ni escamotear el presente.

En consecuencia, lo que moviliza a actrices / actores a emitir sus discursos son intereses sociales, políticos y económicos en un momento histórico determinado, dando origen a una arena social de disputas, el denominado campo juridico local (Bourdieu, 1985, 1986; Jenkins, 1991).

Los discursos del Dictamen Ético del CONAR y el Recurso de Protección interpuesto por Fundación Instituto de la Mujer son textos que se caracterizan por ser: Técnicos, en cuanto tratan de aspectos jurídicos que requieren una formación especializada; Estratégicos, porque las actrices / actores buscan con su discurso aumentar sus márgenes de acción posible frente a la contraparte; $y$, finalmente, son UltraRacionalizados, esto es, bajo una arquitectura retórica de complejidad variable subyacen intencionalidades que movilizan las enunciaciones (Andueza, 2004a).

Entre actrices / actores, Marcela Ballara, Fundación Instituto de la Mujer; FES y CONAR, se produce una interacción social discursiva (Van Dijk, 2001a, 2001b), situada bajo condiciones de producción y de reconocimiento (Verón, 1987). Respecto de las primeras pueden citarse: La Constitución, las leyes, el Código Chileno de Ética Publicitaria y las Conven- ciones que protegen a la Mujer ${ }^{6}$; Cultura patriarcal, y muerte de mujeres víctimas de violencia.

Respecto de las condiciones de reconocimiento, se encuentra el Recurso de Protección interpuesto por la Fundación Instituto de la Mujer mediante el cual dota de sentido la interacción social discursiva.

A continuación se explicará en qué sentido son condiciones de producción para los discursos los elementos señalados con anterioridad.

En primer lugar, Chile tiene una cultura patriarcal donde año tras año mueren mujeres víctimas de violencia ${ }^{7}$, creando un contexto dentro del cual los discursos reciben una impronta, y la posibilidad de ser significados por las actrices / actores dentro de la cultura de la cual forman parte. Además de ello, la Constitución, las leyes, el Código Chileno de Ética Publicitaria y las Convenciones que protegen a la Mujer son normas para el comportamiento, siendo, en particular, las leyes, declaraciones que mandan, prohíben o permiten y están dotadas de capacidad de obligar. Son fuentes de protección como de control para actrices / actores en un conflicto (Andueza, 2004b; Código Civil de Chile, 1999; Leibniz, 1984). Así consideradas, las leyes, son marcos normativos que operan como conjunto de reglas insoslayables para la enunciación discursiva, por tanto, el discurso como texto, es "lo posible de decir" respecto del Objeto: Contenido del Anuncio Publicitario.

6 En particular se hace referencia a las siguientes fuentes [CPE]: Art. $19 \mathrm{~N}^{\circ} 1$ Derecho a la Vida y a la Integridad Física y Psíquica de la Persona, $19 \mathrm{~N}^{\circ}$ 2, la Igualdad Ante la Ley y el deber de no discriminación, Art. $19 \mathrm{~N}^{\circ} 4$ Respeto y Protección a la vida privada y pública y a la honra de la persona y su familia, Art. $19 \mathrm{~N}^{\circ} 12$, la Libertad de Expresión, Art. 13 de la Convención Americana de Derechos Humanos, $19 \mathrm{~N}^{\circ} 21$, Derecho a desarrollar cualquier actividad económica teniendo la moral como límite. La Convención para la Eliminación de todas las Formas de Discriminación contra la Mujer, ratificada por Chile en 1989, Art. 2, Ictra c y aplicable en virtud del Art. 5, inc. 2 [CPE]; la Convención Interamericana para Prevenir, Sancionar y Erradicar la Violencia contra la Mujer, Art. 1 y 8, g; Convención de los Derechos del Niño, Art. 3 sobre el Interés superior del Niño y el Código Chileno de Ética Publicitaria, Art. $3^{\circ}$. La trascripción completa de los artículos senalados supera con creces los límites para el presente articulo, por tanto, deberán consultarse en su fuente original.

7 Mueren más de 70 mujeres por año víctima de violencia intrafamiliar; Carabineros recibe más de 80.000 denuncias por violencia intrafamiliar que afectan su integridad fisica, psicológica y/o sexual (Fundación Instituto de la Mujer, 2005). 
La cultura puede definirse como "[...] sistemas en interacción de signos interpretables ([...] símbolos), la cultura no es una entidad, algo a lo que puedan atribuirse de manera causal [...] modos de conducta, [...] o procesos sociales; [...] es un contexto dentro del cual pueden describirse todos estos fenómenos de manera inteligible, es decir, densa" (Geertz, 1973, p. 27). De este modo, quedan sentadas las bases para pensar la interacción social discursiva como un entramado simbólico al cual es posible conferir sentido y significado, en otras palabras, es posible de interpretar, considerando los discursos de actrices / actores como textos (Riccoeur, 1986).

La cultura por los procesos sociales que designan, es un entramado simbólico estructurante para actrices / actores que enuncian un discurso, pues este, cristaliza un sentido, en este caso, respecto del Objeto: Contenido Publicitario.
La Constitución, las leyes, el Código Chileno de Ética Publicitaria y las Convenciones que protegen a la Mujer; Cultura patriarcal y la muerte de mujeres víctimas de violencia operan como Condiciones de Producción $\mathrm{P}\left(\mathrm{D}_{\mathrm{i}} / \mathrm{D}_{\mathrm{ii}}\right)$, esto significa que este conjunto extra-textual deja "huellas" mediante operaciones discursivas particulares sobre la superficie de los Discursos -de las actrices / actores- contenido en el Fallo del CONAR $\left(D_{i}\right)$ y en el Recurso de Protección interpuesto por Fundación Instituto de la Mujer, $\left(D_{i i}\right)$. A su vez, $\left(D_{i j}\right)$ deviene en interpretante respecto de $\left(D_{i}\right)$, dando lugar a $R\left(D_{i i}\right)$ que otorga un sentido mediante el Recurso de Protección interpuesto por Fundación Instituto de la Mujer a la interacción discursiva. Así, cada discurso fija un modo particular de definir y dotar de significado al Objeto $\left(\mathrm{O}_{\mathrm{i}} / \mathrm{O}_{\mathrm{ij}}\right)$ : Contenido Publicitario (Verón, 1987).

Figura 1. Las Relaciones de un Discurso con sus Condiciones de Producción

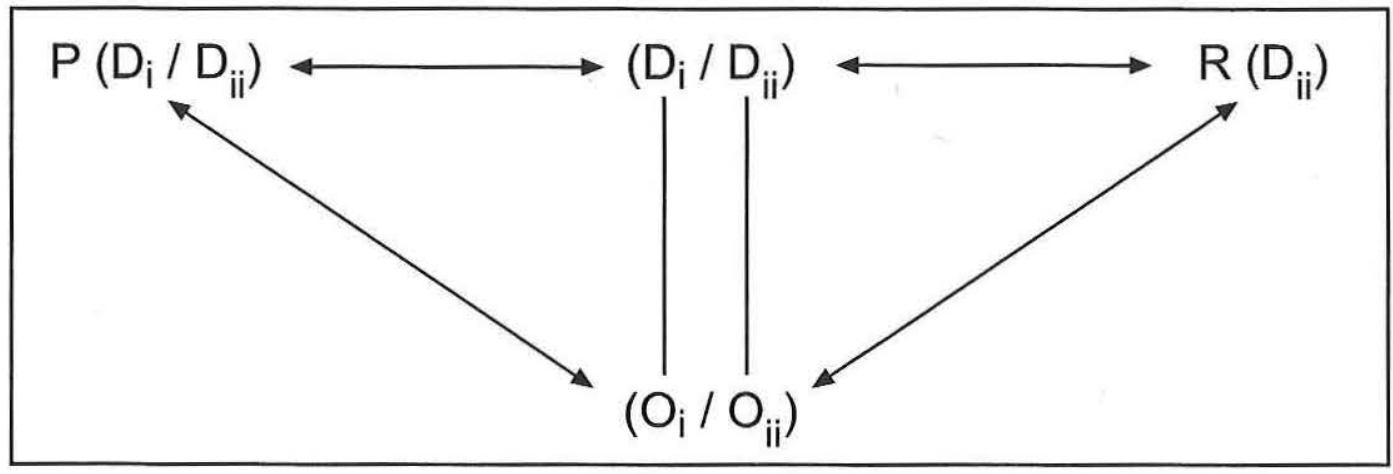

Finalmente es posible establecer las siguientes hipótesis:

a) "Toda producción de sentido es necesariamente social: no se puede describir ni explicar satisfactoriamente un proceso significante, sin explicar sus condiciones sociales productivas" (Verón, 1987, p. 125).

b) "Todo fenómeno social es, en una de sus dimensiones constitutivas, un proceso de producción de sentido, cualquiera que fuere el nivel de análisis" (Verón, 1987, p. 125).

Las actrices / actores sociales emiten sus discursos por intereses sociales políticos y económicos en un momento histórico determinado, dando origen a una arena social de disputas: el campo jurídico local (Bourdieu, 1985, 1986; Jenkins, 1991) donde realizan su interacción social discursiva respecto del Objeto: Conteni- do del Anuncio Publicitario. La interacción social discursiva que da origen al campo jurídico local manifiesta las diferentes perspectivas de hombres y mujeres en una sociedad patriarcal con una marcada asimetría del poder.

La perspectiva teórica construida define conflicto como una situación donde las partes perciben una incompatibilidad actual o futura, en tanto desean satisfacer intereses y necesidades que son incompatibles. Además existe una presión hacia la decisión, pues de lo contrario, es eludible el conflicto (Andueza, 2004a; Myers, 1995; Rodríguez, 1995). Este último aparece en el campo jurídico local bajo la forma de una interacción social discursiva asentada en Procesos Psicosociojurídicos (Galván, 2003):

En primer lugar, las actrices / actores realizan solicitudes sobre algo que se desea, con ello 
establecen posiciones. Estas a su vez se fundamentan en argumentaciones cuya finalidad es defender intereses que buscan satisfactores específicos. Las categorías mencionadas son agrupadas bajo el rótulo de Aspectos Situacionales.

En segundo lugar cada parte describe de modo interpretativo lo que sucede estableciendo explicaciones causales mediante percepciones y atribuciones ligadas a conjuntos de creencias respecto de la otra parte y sobre el conflicto, denominadas cogniciones. Lo señalado conforma los Procesos Psicosociales Básicos.

En tercer lugar actrices / actores tienen varias posibilidades de realizar juegos de poder, por tanto poseen una diversificación de relaciones específica que depende de los recursos pertinentes, del tiempo disponible y de las leyes. Corresponden a las Fuentes del Poder.

En cuarto lugar los procesos psicosociojurídicos precedentes son un conglomerado de acciones adoptadas por actrices / actores, describiendo estrategias específicas.
En el conflicto que se analizará - tal como se ha señalado-, FES, al no acatar el Dictamen Ético del CONAR, la Fundación Instituto de la Mujer recurre a Tribunales, es decir, se opta por un modelo del orden impuesto donde la autoridad entrega al juez el imperio de la fuerza y las partes reconocen el legítimo poder de la magistratura, sometiéndose a su veredicto (Andueza, 1997) si este se ajusta a derecho y no proceden otros recursos según la ley.

A continuación se profundizan los conceptos de los procesos psicosociojurídicos en las "Matrices para Diagnosticar un Conflicto: Categorías de Análisis" y se especifican los "Niveles de Análisis de las Matrices"; para finalizar con la "Figura $\mathrm{N}^{\circ} 2$ : Esquema Teórico y Metodológico para una Psicología Social Jurídica del Discurso en sus Condiciones de Producción", donde se condensa la perspectiva trazada para la presente investigación.

Matrices para Diagnosticar un Conflicto: Categorías de Análisis

\begin{tabular}{|c|c|c|}
\hline Aspectos Situacionales & Procesos Psicosociales Básicos & Fuentes del Poder \\
\hline $\begin{array}{l}\text { Posición: Es una aspiración, una } \\
\text { solicitud de algo que se desea. Es } \\
\text { el derecho que se cree tener sobre } \\
\text { algo, lo cual se manifiesta con la } \\
\text { exigencia de una subordinación de } \\
\text { un interés ajeno a un interés pro- } \\
\text { pio (Aldea, 1989 citado en } \\
\text { Castellón, 2004; Quijada, 1994; } \\
\text { Carnelutti, 1944b) }\end{array}$ & $\begin{array}{l}\text { Percepción: Es la descripción de } \\
\text { la situación, lo central que ocurre } \\
\text { según cada parte. Es el proceso por } \\
\text { el cual se reúne e interpreta la in- } \\
\text { formación. Sirve como enlace me- } \\
\text { diador entre el individuo y su am- } \\
\text { biente (Demicheli, 2004; Vander, } \\
\text { 1994). }\end{array}$ & $\begin{array}{l}\text { Diversificación de Relaciones: } \\
\text { Son las posibilidades que un actor } \\
\text { tiene de jugar varias relaciones de } \\
\text { poder a la vez. De hecho, esto le } \\
\text { permitirá, por un lado, protegerse } \\
\text { contra riesgos de pérdidas inheren- } \\
\text { tes a las relaciones de poder, y, por } \\
\text { otro lado, acumular recursos de } \\
\text { otras relaciones, mejorando las po- } \\
\text { sibilidades de desarrollar juegos } \\
\text { ofensivos (Crozier \& Friedberg, } \\
1977 \text { citado en Andueza, 2004b). }\end{array}$ \\
\hline $\begin{array}{l}\text { Argumentación: Es el uso de ra- } \\
\text { zonamientos mediante los cuales } \\
\text { se intenta probar, demostrar o re- } \\
\text { futar algo (una tesis), convencien- } \\
\text { do a alguno de la verdad o false- } \\
\text { dad de la misma (Castellón, 2004; } \\
\text { Ferrater, 1965). }\end{array}$ & $\begin{array}{l}\text { Cognición: Son las ideas, creen- } \\
\text { cias generales que cada parte tiene } \\
\text { respecto de la otra y del problema } \\
\text { (Demicheli, 2004). }\end{array}$ & $\begin{array}{l}\text { Recursos Pertinentes: Son pro- } \\
\text { cesos relacionales como la fuerza, } \\
\text { la riqueza, el prestigio y la autori- } \\
\text { dad (aspectos simbólicos y mate- } \\
\text { riales), que en un conflicto deter- } \\
\text { minado, confieren una libertad de } \\
\text { acción mayor o menor a los acto- } \\
\text { res (Andueza, 2004a, 2004b; } \\
\text { Crozier \& Friedberg, 1977). }\end{array}$ \\
\hline
\end{tabular}




\begin{tabular}{|c|c|c|}
\hline $\begin{array}{l}\text { Interés: Son las "razones", gene- } \\
\text { ralmente implícitas, que movilizan } \\
\text { las interacciones sociales; no obe- } \\
\text { decen, necesariamente, a un cálcu- } \\
\text { lo racional consciente. Son deman- } \\
\text { das, deseos, juicios, mediante los } \\
\text { cuales se manifiesta una posición } \\
\text { favorable a la satisfacción de una } \\
\text { necesidad, en el plano individual o } \\
\text { colectivo. Son pretensiones funda- } \\
\text { das o susceptibles de ser fundadas } \\
\text { en el Derecho (Bourdieu, 1997; } \\
\text { Machiavello, 1990 citado en } \\
\text { Castellón, 2004; Hoyos, 1987; } \\
\text { Rocco, 1969; Orgaz, 1961; } \\
\text { Carnelutti, 1944a). }\end{array}$ & $\begin{array}{l}\text { Atribución: Son las explicaciones } \\
\text { causales que cada parte invoca res- } \\
\text { pecto del conflicto y del compor- } \\
\text { tamiento de la otra parte. Este es el } \\
\text { proceso mediante el cual se inter- } \\
\text { preta y explica la conducta tanto } \\
\text { propia como ajena. Finaliza, al en- } \\
\text { contrar una causa que se considera } \\
\text { verosímil. Esta causa puede ser } \\
\text { entendida como una disposición } \\
\text { interna (rasgos, motivos y actitu- } \\
\text { des perdurables) o referida a situa- } \\
\text { ciones externas (Demicheli, 2004; } \\
\text { Moya, 1994; Myers, 1995; Vander, } \\
\text { 1994). }\end{array}$ & $\begin{array}{l}\text { Leyes: Son declaraciones que } \\
\text { mandan, prohíben o permiten y } \\
\text { están dotadas de capacidad de } \\
\text { obligar. La utilización de las leyes } \\
\text { pertinentes, tribunales y asesoría } \\
\text { jurídica son fuentes de protección } \\
\text { como de control para los actores } \\
\text { involucrados en el conflicto } \\
\text { (Andueza, 2004b; Código Civil de } \\
\text { Chile, 1999; Leibniz, 1984). }\end{array}$ \\
\hline $\begin{array}{l}\text { Satisfactores: Representan for- } \\
\text { mas de ser, tener, hacery estar, que } \\
\text { contribuyen a la realización o ac- } \\
\text { tualización de las necesidades hu- } \\
\text { manas (que son a su vez carencia- } \\
\text { potencialidad) individuales y co- } \\
\text { lectivas (Max-Neef, Elizalde \& } \\
\text { Hopenhayn, 1986). }\end{array}$ & & $\begin{array}{l}\text { Tiempo Disponible: Es un factor } \\
\text { que puede aumentar o disminuir la } \\
\text { diversificación de relaciones y las } \\
\text { estrategias que los actores pueden } \\
\text { utilizar en un conflicto, transfor- } \\
\text { mándose así en un aspecto a favor } \\
\text { o en contra en las relaciones de } \\
\text { poder entre los actores (Andueza, } \\
\text { 2004b; Crozier \& Friedberg, 1977) }\end{array}$ \\
\hline \multicolumn{3}{|c|}{$\begin{array}{l}\text { Estrategias: Son las diversas acciones que adoptan los actores en un conflicto. Estas acciones no obedecen } \\
\text { necesariamente a conductas calculadas, a objetivos claros ni a proyectos coherentes, se caracterizan por ser } \\
\text { activas. Poseen siempre un doble aspecto: uno ofensivo, que es el uso de oportunidades en miras a mejorar su } \\
\text { situación, y uno defensivo, que es la mantención y ampliación del margen de libertad, por tanto, de su capaci- } \\
\text { dad de actuar, que si bien siempre está limitada, no está jamás determinada. Por tanto, las estrategias no son } \\
\text { comportamientos irracionales (aunque sí, a veces erráticos). Más allá de los eventuales vaivenes emocionales, } \\
\text { y las diversas conductas de un actor, hay regularidades que siempre tienen un sentido. Justamente en función } \\
\text { de una estrategia. Ejemplos: hacer público un problema, organizarse en asociaciones o corporaciones, politizar } \\
\text { condescender con los oponentes, judicializar el caso, búsqueda de alianzas, etc. (Andueza, 2004b; Crozier \& } \\
\text { Friedberg, 1977). }\end{array}$} \\
\hline
\end{tabular}

Los Niveles de Análisis de las Matrices*

\begin{tabular}{|c|c|c|c|}
\cline { 2 - 4 } \multicolumn{1}{c|}{} & \multicolumn{3}{|c|}{ NIVEL DE ANÁLISIS } \\
\cline { 2 - 4 } & Descriptivo & Interpretativo & Explicativo \\
\hline CóDIGOS & Fuentes del Poder & Intereses \\
Argumentaciones & Percepciones & Cogniciones \\
& Satisfactores & Atribuciones & Poder \\
& & Diversificación de & \\
& & Relaciones & \\
& & Recursos Pertinentes & \\
& & Leyes & \\
\hline
\end{tabular}


Figura $N^{\circ}$ 2: Esquema Teórico y Metodológico para una Psicología Social Jurídica del Discurso en sus Condiciones de Producción.

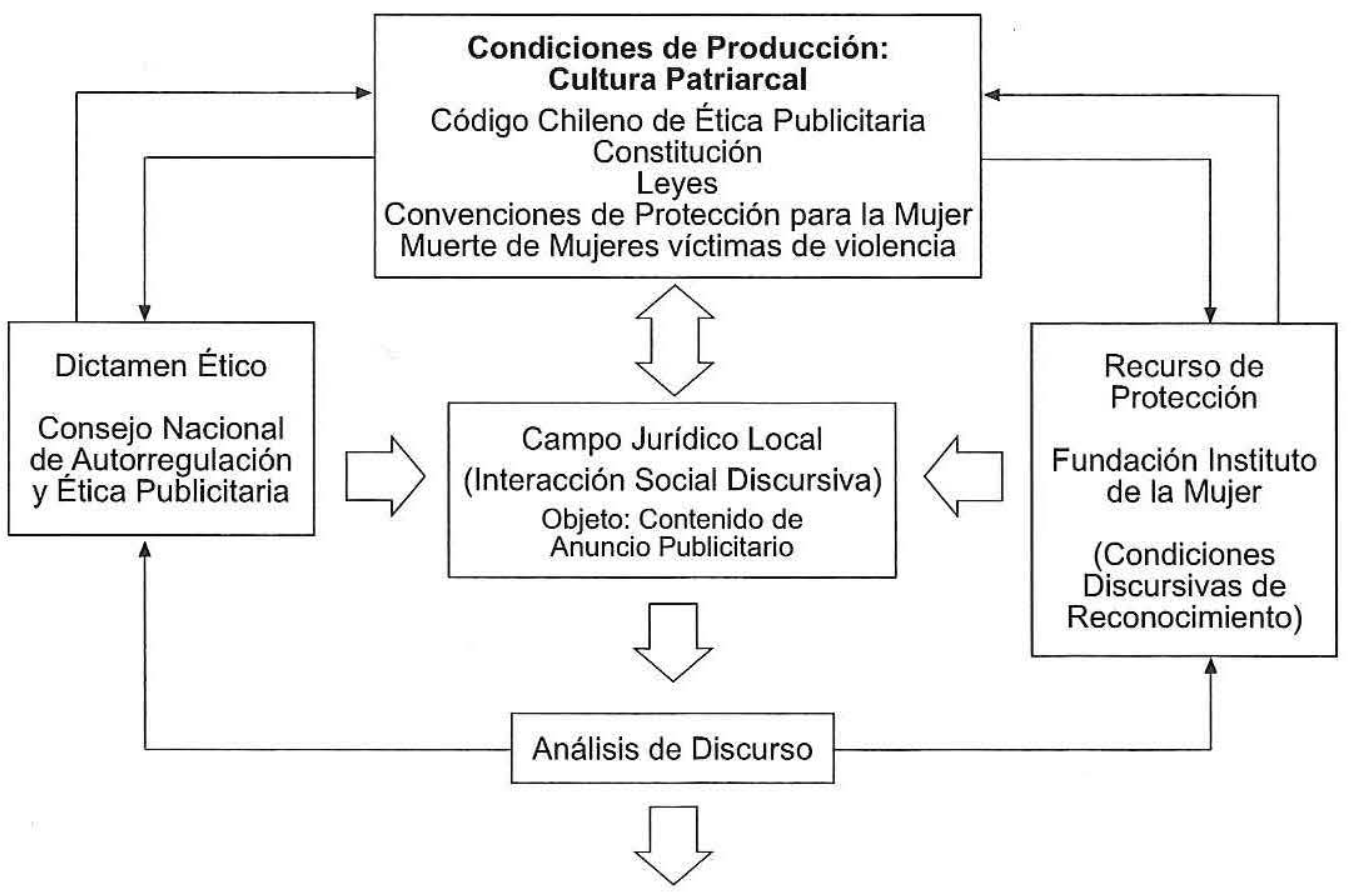

\section{Matrices para Diagnosticar un Conflicto}

\subsection{Características de la Cultura Patriarcal}

Nuestra cultura occidental se caracteriza por la guerra, la competencia, las luchas, las jerarquías, la autoridad, el poder, el control y la dominación basada en la apropiación de la verdad como única, trascendental y obligatoria. Por eso vivimos básicamente en desconfianza de la autonomía de los otros / de las otras. En cada momento alguien se apropia del derecho a decidir lo que es legítimo o adecuado para nuestras vidas con criterios que son esgrimidos como ne- cesarios, no aceptando los desacuerdos. Sólo se acepta a quien piensa diferente cuando existe un convencimiento de que será posible llevar a él o ella hacia el camino "correcto" que es nuestro, de no ser así, su eliminación aparece como justificación bajo el pretexto de que estaba equivocado / equivocada (Maturana, 1993). En este contexto debemos entender el conflicto psicosocial jurídico a estudiar. A continuación se presentará un cuadro que sintetiza las características de la cultura patriarcal según Maturana, 1993.

Características de Cultura Patriarcal

\begin{tabular}{|l|l|}
\hline $\begin{array}{l}\text { 1. La sexualidad de las mujeres se asocia a la pro- } \\
\text { creación y queda bajo el control del patriarca. }\end{array}$ & $\begin{array}{l}\text { 5. El pensamiento es lineal y se vive en la exigencia } \\
\text { de sumisión a la autoridad y la negación de lo dife- } \\
\text { rente. }\end{array}$ \\
\hline $\begin{array}{l}\text { 2. Las relaciones interpersonales surgen basadas prin- } \\
\text { cipalmente en la autoridad, obediencia y control. }\end{array}$ & $\begin{array}{l}\text { 6. Lo místico se vive relacionado a la subordinación } \\
\text { a una autoridad cósmica y trascendental que requiere } \\
\text { obediencia y sumisión. }\end{array}$ \\
\hline $\begin{array}{l}\text { 3. La guerra y la competencia surgen como modos } \\
\text { naturales de convivencia y aun como valores y virtu- } \\
\text { des. }\end{array}$ & $\begin{array}{l}\text { 7. Se valora la procreación y se abomina de cualquier } \\
\text { noción o acción de control de la natalidad. }\end{array}$ \\
\hline 4. Las conversaciones versan sobre la apropiación. & $\begin{array}{l}\text { 8. Surge el vivir patriarcal de hombres, mujeres y ni- } \\
\text { nos, a lo largo de toda la vida como un proceso natu- } \\
\text { ral. }\end{array}$ \\
\hline
\end{tabular}




\section{Objetivos}

\section{Objetivo General:}

Diagnosticar, con una perspectiva de Géne$r o$, el conflicto psicosocial jurídico entre Fundación Instituto de la Mujer y la tienda FES, por contenido de anuncio publicitario.

\section{Objetivos Especificos:}

1. Identificar los Aspectos Situacionales implicados en el conflicto psicosocial jurídico entre Fundación Instituto de la Mujer y FES.

2. Identificar los Procesos Psicosociales Básicos implicados en el conflicto entre Fundación Instituto de la Mujer y FES.

3. Identificar las Fuentes del Poder de la Fundación Instituto de la Mujer y FES, relacionadas con el conflicto psicosocial jurídico, a partir de un análisis crítico de los discursos en sus Condiciones de Producción (cultura patriarcal, muerte de mujeres víctimas de violencia, la Constitución, las leyes y Convenciones que protegen a la Mujer) y sus Condiciones de Reconocimiento (Recurso de Protección).

4. Identificar las Estrategias utilizadas por la Fundación Instituto de la Mujer y FES en el conflicto psicosocial jurídico.

\section{Preguntas Directrices}

1. ¿Cuáles son los Aspectos Situacionales implicados en el conflicto psicosocial jurídico entre Fundación Instituto de la Mujer y FES?

2. ¿Cuáles son los Procesos Psicosociales Básicos implicados en el conflicto entre Fundación Instituto de la Mujer y FES?

3. ¿Cuáles son las Fuentes del Poder de la Fundación Instituto de la Mujer y FES, relacionadas con el conflicto psicosocial jurídico, a partir de un análisis crítico de los discursos en sus Condiciones de Producción (cultura patriarcal, muerte de mujeres víctimas de violencia, la Constitución, las leyes y Convenciones que protegen a la Mujer) y sus Condiciones de Reconocimiento (Recurso de Protección)?

4. ¿Cuáles son las Estrategias utilizadas por la Fundación Instituto de la Mujer y FES?
5. ¿Existen formas de victimización colectiva primaria y/o secundaria de la Mujer en el conflicto psicosocial jurídico entre Fundación Instituto de la Mujer y la tienda FES?

\section{Marco Metodológico}

\section{Análisis Crítico de Discurso}

El Análisis Crítico de Discurso [ACD], puede ser caracterizado de la siguiente manera:

- Construye un planteamiento teórico y metodológico que permite estudiar problemas sociales $^{8}$ relevantes (Ej.: sexismo, racismo) $\mathrm{u}$ otras formas de desigualdad social (Van Dijk, 1987).

- Es un planteamiento, posicionamiento o postura explícitamente crítico para estudiar el texto y el habla (Van Dijk, 1987).

- Forma parte del espectro de estudios críti$\cos$ (a menudo marginales o marginalizados) sobre Humanidades y Ciencias Sociales (Van Dijk, 1987).

- Se centra fundamentalmente en las relaciones de poder; dominación y desigualdad, describiendo los procesos mediante los cuales existe reproducción, oposición y resistencia social de clase, género, étnicas, raciales, de orientación sexual, edad, etc. (Van Dijk, 1987).

- Es un esfuerzo por descubrir, revelar o divulgar aquello implícito en las relaciones de dominación discursiva. Por tanto la adopción de una perspectiva crítica conlleva una oposición contra las elites y los que ocupan el poder, especialmente cuando existe $a b u-$ so de poder(Van Dijk, 1987).

\footnotetext{
8 "Existe un problema social cuando un grupo de influencia es consciente de una condición social que afecta a sus valores, y que puede ser remediada por una acción colectiva " (Sullivan et al., 1980 citado en Clemente, 1992, p. 16). A su vez, se entenderá por condición social "[...] la caracteristica en cuya presencia nace un problema social, siendo por tanto cl problema social más bien la consecuencia, o mejor dicho uno de los posibles productos que se manifiestan al estar presente tal condición social" (Clemente, 1992, p. 13). El actual caso en estudio es un problema social porque Marcela Ballara y la Fundación Instituto de la Mujer al recurrir al CONAR existe una toma de conciencia sobre la muerte de Mujeres por violencia intrafamiliar (condición social) y respecto de la violencia contra la Mujer presente en el anuncio publicitario de FES, como un atentado contra valores como el respeto y la dignidad de la Mujer (problema social).
} 
- Es solidario con los grupos dominados formulando estrategias que desarrollen un contrapoder cuando se dé la práctica de confrontación y de resistencia (Van Dijk, 1987).

- Introduce en la investigación cualitativa una ética social en tanto el ACD asume que la labor académica tiene un carácter político, a través de la elección temática, métodos y teorías en el estudio del discurso. Por cierto que el carácter "político" no es "partidista" sino de compromiso, solidaridad con aquellos / as que en una relación de poder se encuentran en una condición de mayor desventaja. Así, una acción es crítica si actúa en contra de los modos tradicionales, vigentes y oficiales de interpretación de la realidad, adoptando una postura epistemológica que deviene como estrategia: la desarticulación de los discursos mediante el análisis (GarcíaBorés, 1996; Van Dijk, 1987).

- Es una perspectiva problematizadora que permite abrir nuevas perspectivas de estudio y nuevos objetos de investigación mediante una teoría que no preconfigura ni determina linealmente el campo de exploración mediante el análisis (Íñiguez, 2003).

\section{Tipo de Investigación}

La investigación es de tipo exploratorio, porque "[...] el objetivo es examinar un tema o problema de investigación poco estudiado o que no ha sido abordado antes" (Hernández, Fernández \& Baptista, 1991, p. 58), lo cual queda de manifiesto, pues no existen investigaciones previas en Chile $^{9}$ sobre el tema de análisis de conflictos de carácter psicosocial jurídico desde una perspectiva de género.

Se utiliza para estudiar el conflicto entre la Fundación Instituto de la Mujer y FES, un método de análisis de discurso, definido como el "estudio de las prácticas lingüísticas para poner de manifiesto las relaciones sociales promovidas y mantenidas por el discurso" (Íñiguez, 2003, p. 202). Así, la categoría género permite situar la interacción social discursiva en las Condiciones de Producción y Reconocimiento.

\footnotetext{
9 A partir de una búsqueda mediante Internet en Chile: Base de Datos del Colcgio de Psicólogos, catálogos de Universidades y Revistas de Psicologia. Se ha abarcado el período (1995-2005).
}

\section{Diseño}

De acuerdo a la nomenclatura tradicional, el Diseño de esta investigación es No Experimental, Transeccional o Transversal, de Corte Cualitativo, basado en el Caso Único de tipo Instrumental.

El Caso Único se define "como un sistema acotado [...] en su condición de objeto más que de proceso [...]" (Smith, 1979 citado en Stake, 1995, p. 16). Este tipo de estudio permite formular "[...] determinadas generalizaciones para el caso" (Stake, 1995, p. 19). Aumentando en especificidad, se señala que el Estudio de Caso es de Tipo Instrumental (Stake, 1995), porque al estudiar el conflicto psicosocial jurídico entre la Fundación Instituto de la Mujer y la tienda FES, existe "[...] una necesidad de comprensión general [de los Discursos en sus condiciones de producción] y consideramos que podemos entender la cuestión mediante el estudio de un caso particular" (Stake, 1995, p. 16). Por cierto que "un caso particular" está conceptualizado en esta investigación como un caso "psicosocial", adscribiéndose al enfoque de una Psicología Social Jurídica del Discurso en sus Condiciones de Producción.

\section{Corpus}

Está compuesto por 2 discursos correspondientes al Dictamen Ético del CONAR y el Recurso de Protección interpuesto por la Fundación Instituto de la Mujer, más la opinión de Marcelo Konitzki, representante de FES, a la Prensa (Lechuga, 2005). En estos discursos se encuentran las perspectivas de las actrices / actores en conflicto.

\section{Procedimientos ${ }^{10}$}

1. Es necesario leer la totalidad del discurso del Dictamen Ético del CONAR para formarse una idea preliminar y general de las perspectivas que tienen las actrices y actores en conflicto.

2. Establecer las Perspectivas sobre el Objeto: Contenido de Anuncio Publicitario. Se aplican las categorías correspondientes a cada una de las matrices*, en el siguiente orden:

${ }^{10}$ Considerando los objetivos de la presente investigación, se ha adaptado el Procedimiento de Análisis Estructural de Discurso (Venegas, 2006).

- Ver Matrices para Diagnosticar un Conflicto: Categorias de Análisis. 
Análisis de los Aspectos Situacionales, Procesos Psicosociales Básicos, Fuentes del Poder $^{* *}$ y Estrategias ${ }^{* * *}$.

3. Una vez completadas las matrices correspondientes, ¿̨Cuál es el diagnóstico - desde una perspectiva de Género- del Conflicto psicosocial jurídico entre Fundación Instituto de la Mujer y la tienda FES, por contenido de anuncio publicitario?

\section{Presentación de los Resultados}

El análisis de los discursos será descrito a partir de una descripción que recogerá las principales convergencias y divergencias entre las actrices / actores en conflicto. Luego se mostrarán a las Matrices para Diagnosticar un Conflicto, las cuales permiten sintetizar gran cantidad de datos cualitativos (Huberman \& Miles, 1992).

\section{Análisis de los Datos}

\section{Descripción para la Matriz I: Análisis Situacional}

La Actriz 1 Marcela Ballara y la Actriz 2 Fundación Instituto de la Mujer han sido colocadas en una misma columna pues en lo substancial comparten perspectivas. Sus Posiciones son coincidentes en señalar: "La publicidad de la tienda FES debe ser retirada". Mostrando una cercanía con esta posición (indicado con la línea punteada vertical en la matriz) el CONAR mediante su dictamen ético afirma: "la publicidad cuestionada no debiera continuar exhibiéndose". En contraste con lo anterior FES afirma que la publicidad de la tienda debe mantenerse.

Las Argumentaciones de las actrices se desglosan así, Marcela Ballara sostiene: FES "tiene un marketing que llama a la violencia, especialmente la juvenil". Mientras la Funda-

\footnotetext{
- Esta matriz se completa mediante un análisis interpretativo respecto a los registros cualitativos de la Diversificación de Relaciones, Recursos Pertinentes y (Código) / Leyes.

-. Esta matriz se completa considerando de modo global los datos cualitativos proporcionados por las matrices precedentes, ya que así es posible advertir las regularidades de las acciones adoptadas por las actrices / actores en el conflicto psicosocial jurídico.

Las últimas dos notas vienen a poner de manifiesto que los "Niveles de Análisis de las Matrices" son distintos tal como lo señalara en el respectivo cuadro.
}

ción Instituto de la Mujer con conocimiento del encuadre legal destaca que se "vulnera el Art. 3 del Código Chileno de Ética Publicitaria" mostrando violencia excesiva con su publicidad, afectando a hombres y mujeres con la finalidad de promocionar su marca. En este sentido, el CONAR también estima que se vulnera el mencionado artículo (indicado con la línea punteada vertical en la matriz) agregando que el contenido publicitario impacta por su crudeza y realismo, exhibiendo violencia innecesaria sin un contexto que la explique, desestimando la argumentación de FES respecto al carácter cinematográfico del contenido y la percepción de irrealidad por parte del público receptor del mensaje. Sin embargo FES insiste en que no se vulnera el artículo aludido pues la publicidad no apoya ni induce a la violencia. Más aún, no puede transformarse el contenido vertido en ella en hechos de la realidad.

Lo analizado hasta el momento comprende una primera fase del conflicto donde Marcela Ballara y la Fundación Instituto de la Mujer recurren al CONAR el 13/04/2005, organismo que elabora un Dictamen Ético el 25/04/2005 (CONAR, 2005), que no es acatado por FES. Así se abre una segunda fase del conflicto donde la Fundación Instituto de la Mujer presenta ante la Corte de Apelaciones de Santiago un Recurso de Protección el 19/05/05 (Lechuga, 2005). Estos dos momentos son indicados en esta matriz y en las siguientes mediante una doble línea horizontal.

En el segundo momento del conflicto la actriz 1 Marcela Ballara deja de aparecer, para adoptar un rol protagónico la Fundación Instituto de la Mujer; quien presenta el Recurso de Protección Argumentando que FES no ha respetado el Dictamen Ético del CONAR. Por su parte al CONAR ya no le corresponde intervenir puesto que ha usado las atribuciones por ley establecidas (indicado con línea horizontal en el casillero de la matriz) ${ }^{11}$. Este último aspecto es aprovechado por FES Argumentando que en tanto el CONAR no es una entidad legal evaluaron la situación (el Dictamen) y aún así mantuvieron la publicidad.

Los Intereses de la Actriz 1 y 2 son defender los derechos de mujeres y hombres, siendo agregado en el segundo momento del conflicto, por

"Para cl resto del análisis de las matrices, se da por establecido este punto, no se volverá a insistir en cllo. 
la Fundación Instituto de la Mujer la defensa de los niños. Para el CONAR, en la primera fase del conflicto, también defiende a mujeres y niños agregando, por cierto, salvaguardar principios éticos de la publicidad, siendo esa su labor específica. En este sector de la matriz (indicada con las líneas punteadas verticales) se aprecia una coincidencia entre las Actrices $\mathrm{N}^{\circ} 1,2$ y el Actor 3. En contraste FES busca proteger la inversión económica realizada por la tienda en la publicidad. En el segundo momento del conflicto, en tanto aún no es citado a declarar por tribunales el representante de FES, se ha dejado indicado con un signo de interrogación ${ }^{12}$. Si bien, en principio, puede pensarse en una mantención del interés, en estricto rigor, no puede establecerse hasta que empíricamente se cuente con el documento presentado por FES donde realice sus descargos ante la Corte de Apelaciones de Santiago.

Los Satisfactores para las Actrices $\mathrm{N}^{\circ} 1,2$ es la acogida de la Denuncia realizada al CONAR y el acatamiento del Dictamen Ético por parte de FES. Respecto a lo primero existe una convergencia con FES que acoge la denuncia y recomienda el retiro de la publicidad. Sin embargo FES opta por mantener la publicidad. Esto lleva a la Fundación Instituto de la Mujer a solicitar, mediante el Recurso de Protección, ordenar el retiro del aviso y de cualquier forma de reproducción del mismo avisando a Carabineros; declarando el cobro de perjuicios y costas. Por parte de FES aún no se cuenta con el documento presentado ante tribunales donde realice los descargos, por tanto no han podido establecerse los satisfactores específicos (lo cual se ha indicado con un signo de interrogación).

El conflicto pone de manifiesto la cultura Patriarcal: Negación de lo diferente, FES no acepta otra interpretación de su Anuncio Publicitario, y no acata el Dictamen del CONAR, porque no es coercitivo, lo que en una cultura basada en el Control y la Autoridad no tiene peso. Así Fundación Instituto de la Mujer debe seguir el camino judicial para entrar en el universo simbólico del Patriarcado.

Matriz I: Análisis Situacional

\begin{tabular}{|c|c|c|c|}
\hline & $\begin{array}{c}\text { Actriz } 1 \text { / Actriz } 2 \\
\text { Marcela Ballara } \\
\text { Fundación Instituto } \\
\text { de la Mujer }\end{array}$ & $\begin{array}{l}\text { Actor } 3 \\
\text { CONAR }\end{array}$ & $\begin{array}{c}\text { Actor } 4 \\
\text { FES }\end{array}$ \\
\hline Posiciones & $\begin{array}{l}\text { La publicidad de la tienda } \\
\text { FES debe ser retirada } \\
\text { (Ballara, 2005 \& Funda- } \\
\text { ción Instituto de la Mujer, } \\
2005 \text { en CONAR, 2005; } \\
\text { Fundación Instituto de la } \\
\text { Mujer, 2005). }\end{array}$ & $\begin{array}{l}\text { (Dictamen Ético:) } \\
\text { "La publicidad cuestiona- } \\
\text { da no debiera continuar } \\
\text { exhibiéndose" (CONAR, } \\
\text { 2005, p. 5). }\end{array}$ & $\begin{array}{l}\text { La publicidad de la tienda } \\
\text { debe mantenerse } \\
\text { (Konitzki, 2005 en } \\
\text { CONAR, 2005; Konitzki, } \\
2005 \text { en Lechuga, 2005). }\end{array}$ \\
\hline Argumentaciones & $\begin{array}{l}\text { "[...] tiene un marketing } \\
\text { que llama a la violencia, } \\
\text { especialmente la juvenil" } \\
\text { (Ballara, 2005 en } \\
\text { CONAR, 2005, p. 2) }\end{array}$ & $\begin{array}{l}\text { "Según lo dispone el artí- } \\
\text { culo } 3^{\circ} \text { del Código Chile- } \\
\text { no de Ética Publicitaria: } \\
\text { "Los mensajes no deben } \\
\text { inducir a realizar o apoyar } \\
\text { actos de violencia en nin- } \\
\text { guna de sus manifestacio- } \\
\text { nes". }\end{array}$ & $\begin{array}{l}\text { "El público receptor del } \\
\text { mensaje, [lo entiende] } \\
\text { como una historia ficticia, } \\
\text { fuera de la realidad, y ba- } \\
\text { sada en la exhibición de } \\
\text { películas ampliamente re- } \\
\text { ceptivas como Pulp } \\
\text { Fiction, Kill Billy/o Con- } \\
\text { tra Cara [...]. En conse- }\end{array}$ \\
\hline
\end{tabular}

12 Según los antecedentes hasta la fecha reunidos para la presente investigación, FES aún no ha presentado sus descargos ante la Corte de Apelaciones de Santiago por tanto el significado del símbolo "?" se seguirá manteniendo para las próximas veces que aparezca en las matrices. 


\begin{tabular}{|c|c|c|c|}
\hline & $\begin{array}{l}\text { "[...] vulnera el Art. } 3 \text { del } \\
\text { Código Chileno de Ética } \\
\text { Publicitaria. En este caso, } \\
\text { esta propaganda utiliza } \\
\text { una escena de violencia } \\
\text { excesiva, que afecta a } \\
\text { hombres y mujeres, con el } \\
\text { objeto de promocionar } \\
\text { una marca de ropa" (Fun- } \\
\text { dación Instituto de la Mu- } \\
\text { jer, 2005 en CONAR, } \\
2005, \text { p. 2). }\end{array}$ & $\begin{array}{l}\text { "Tampoco cree este Di- } \\
\text { rectorio que la incorpora- } \\
\text { ción de la violencia en las } \\
\text { imágenes de la campaña } \\
\text { de FES, constituyan una } \\
\text { parodia, sino que más } \\
\text { bien, corresponden a } \\
\text { montajes que impactan } \\
\text { por su crudeza y realismo" } \\
\text { (CONAR, 2005, p. 4). } \\
\text { "[...] las piezas reclama- } \\
\text { das [...] exhiben situacio- } \\
\text { nes de violencia de una } \\
\text { forma innecesaria e injus- } \\
\text { tificada, sin que exista } \\
\text { tampoco un contexto que } \\
\text { las explique" (CONAR, } \\
2005, \text { p. 4). }\end{array}$ & $\begin{array}{l}\text { cuencia, rechazamos la in- } \\
\text { terpretación que le han } \\
\text { dado las denunciantes, no } \\
\text { pudiendo transformarse la } \\
\text { fantasía contenida en ella } \\
\text { en hechos de la vida coti- } \\
\text { diana, como, erradamente } \\
\text { por cierto, leatribuyen las de- } \\
\text { nunciantes"(Konitzki, 2005 } \\
\text { en CONAR, 2005, pp. 2-3). } \\
\text { "En caso alguno se vulne- } \\
\text { ra el artículo tercero del } \\
\text { Código de Ética, en razón } \\
\text { a que la publicidad cues- } \\
\text { tionada no apoya ni indu- } \\
\text { ce a actos de violencia, } \\
\text { sino es una simple parodia } \\
\text { del tipo de las películas ci- } \\
\text { tadas" (Konitzki, 2005 en } \\
\text { CONAR, 2005, p. 3). }\end{array}$ \\
\hline & $\begin{array}{l}\text { Se presenta un Recurso de } \\
\text { Protección porque la tien- } \\
\text { da FES no ha respetado el } \\
\text { Dictamen Ético del } \\
\text { CONAR (Fundación Ins- } \\
\text { tituto de la Mujer, 2005). }\end{array}$ & & $\begin{array}{l}\text { "[El CONAR] como no es } \\
\text { una entidad legal evalua- } \\
\text { mos la situación y aún así } \\
\text { [se mantuvo] el plan de } \\
\text { medios" (Konitzki, 2005 } \\
\text { en Lechuga, 2005, p. 7). }\end{array}$ \\
\hline Intereses & $\begin{array}{l}\text { Defender los derechos de } \\
\text { mujeres, hombres (...) }\end{array}$ & $\begin{array}{l}\text { Salvaguardar principios } \\
\text { éticos en la publicidad } \\
\text { defendiendo a mujeres y } \\
\text { niños. }\end{array}$ & $\begin{array}{l}\text { Proteger la inversión rea- } \\
\text { lizada por la tienda en la } \\
\text { publicidad. }\end{array}$ \\
\hline & .... y niños. & & i \\
\hline Satisfactores & $\begin{array}{l}\text { Acogida de la Denuncia } \\
\text { realizada a CONAR y } \\
\text { acatamiento del Dictamen } \\
\text { Ético por parte de FES. } \\
\text { "Ordenar el retiro inme- } \\
\text { diato del Aviso Publicita- } \\
\text { rio reclamado de la Tien- } \\
\text { da FES" (Fundación Ins- } \\
\text { tituto de la Mujer, 2005, } \\
\text { p. 8). } \\
\text { "Ordenar el retiro inme- } \\
\text { diato de cualquier forma } \\
\text { de reproducción del aviso } \\
\text { publicitario en todo lugar } \\
\text { público o de venta al pú- } \\
\text { blico, notificando a la Po- } \\
\text { licía de Carabineros de } \\
\text { Chile" (Fundación Institu- } \\
\text { to de la Mujer, 2005, p. 8). } \\
\text { "Decalarar en todo caso, } \\
\text { el cobro de perjuicios en } \\
\text { favor de esta parte, con } \\
\text { costas"(Fundación Institu- } \\
\text { to de la Mujer, 2005, p. 8). }\end{array}$ & $\begin{array}{l}\text { Que FES retire la publici- } \\
\text { dad. }\end{array}$ & Mantener la Publicidad. \\
\hline
\end{tabular}


Descripción para la Matriz II:

Procesos Psicosociales Básicos

La Percepción de la Actriz 1 y 2 si bien tienen matices, se refieren a la brutalidad y a la violencia excesiva que la publicidad contiene afectando a hombres y mujeres. Esto es compartido por el Actor 3, CONAR, quien ratifica la vulneración del Art. $3^{\circ}$ del Código de Ética Publicitaria y el carácter impactante por crudeza y realismo de la publicidad (indicado en la matriz por la línea punteada vertical). En contraposición, el Actor 4, FES, percibe que las denunciantes no han captado el carácter ficticio de la trama publicitaria. En el segundo momento del conflicto, FES insiste en el carácter irreal de la trama publicitaria, en reacción a la Actriz $\mathrm{N}^{\circ} 2$ Fundación Instituto de la Mujer; quien percibe que FES al no acatar el dictamen ético del CONAR, ha incurrido en actos y omisiones arbitrarias e ilegales.

La Cognición de la Actriz 1, Marcela Ballara, -en el primer momento del conflicto-indica que el marketing de FES llama a la violencia, especialmente la juvenil, mostrando con ello una relación causal lineal entre el contenido violento del anuncio y la imitación directa de los jóvenes hacia quienes se dirige el anuncio. Respecto de la Actriz 2 no ha podido inferirse con un grado de certeza aceptable la cognición que subyace a sus planteamientos, siendo indicado en el sector correspondiente de la matriz como "actriz 1 (i)". Respecto del Actor 3, CONAR, indica la toma de conciencia sobre actos de violencia sufridos por mujeres y niños en la sociedad, por lo que los mensajes publicitarios no debieran exhibir imágenes de violencia fuera de contexto. Por su parte FES sostiene que el contenido publicitario es ficticio basándose en una parodia de películas y no susceptible de transformarse la violencia contenida en los anuncios en hechos de la vida real. En el segundo momento del conflicto FES cree que el CONAR en tanto no es una entidad su dictamen ético no es obligatorio acatarlo; en respuesta a la presentación del Recurso de Protección interpuesto por la Fundación Instituto de la Mujer quien cree en la peligrosidad de un camino de tolerancia hacia una publicidad que haga uso de la violencia para aumentar el impacto de su mensaje publicitario, alejándose de la ética y los derechos fundamentales.

La Atribución de la Actriz 1 subraya el llamamiento a la violencia del anuncio, mientras la Actriz 2 se refiere a la vulneración del Art. 3 del Código Chileno de Ética Publicitaria. Esto último es compartido por el Actor 3, CONAR. Por su parte el Actor 4, FES atribuye la raíz del conflicto a un entendimiento errado de las denunciantes respecto del anuncio publicitario. En el segundo momento del conflicto la Atribución de la Fundación Instituto de la Mujer respecto del seguimiento de una vía legal descansa en el incumplimiento por parte de FES del dictamen ético del CONAR. Por su parte FES de modo extrajudicial atribuye el conflicto a que sus "campañas siempre generan polémica" (Lechuga, 2005, p. 7).

En el seno de una sociedad Patriarcal se ve cómo las relaciones entre hombres y mujeres entran en un plano de conflicto legal que no es sino la tensión omnipresente dominador / dominado /a.

Matriz II: Procesos Psicosociales Básicos

\begin{tabular}{|c|c|c|c|}
\hline & $\begin{array}{l}\text { Actriz } 1 \text { / Actriz } 2 \\
\text { Marcela Ballara } \\
\text { Fundación Instituto } \\
\text { de la Mujer }\end{array}$ & $\begin{array}{l}\text { Actor } 3 \\
\text { CONAR }\end{array}$ & $\begin{array}{c}\text { Actor } 4 \\
\text { FES }\end{array}$ \\
\hline Percepción & $\begin{array}{l}\text { "En una tienda de ropa } \\
\text { para jóvenes hay un pós- } \\
\text { ter de aproximadamente } \\
2,5 \text { metros que muestra a } \\
\text { una mujer brutalmente gol- } \\
\text { peada. Dentro de la tienda } \\
\text { hay varios póster con un } \\
\text { joven que tiene una pisto- } \\
\text { la en la boca" (Ballara, } \\
\text { 2005 en CONAR, 2005,p. } \\
\text { 2). }\end{array}$ & $\begin{array}{l}\text { "Las piezas reclamadas se } \\
\text { encuentran en conflicto } \\
\text { con la ética publicitaria" } \\
\text { (CONAR, 2005, p. 4). } \\
\text { "[...] las imágenes de la } \\
\text { campaña FES [no consti- } \\
\text { tuyen..] una parodia, sino } \\
\text { que más bien, correspon- } \\
\text { den a montajes que } \\
\text { impactan por su crudeza y } \\
\text { realismo". }\end{array}$ & $\begin{array}{l}\text { Las denunciantes no han } \\
\text { entendido el carácter fic- } \\
\text { ticio de la trama conteni- } \\
\text { da en el aviso publicitario } \\
\text { (Konitzki, 2005 en } \\
\text { CONAR, 2005). }\end{array}$ \\
\hline
\end{tabular}




\begin{tabular}{|c|c|c|c|}
\hline & $\begin{array}{l}\text { "Consideramos que la pu- } \\
\text { blicidad de la tienda de } \\
\text { ropa juvenil FES vulnera } \\
\text { el artículo tres del Código } \\
\text { Chileno de Ética Publici- } \\
\text { taria. En este caso, esta } \\
\text { propaganda utiliza una es- } \\
\text { cena de violencia excesi- } \\
\text { va, que afecta a hombres } \\
\text { y mujeres, con el objeto de } \\
\text { promocionar una marca } \\
\text { de ropa" (Fundación Ins- } \\
\text { tituto de la Mujer, 2005 en } \\
\text { CONAR, 2005, p. 2). }\end{array}$ & & \\
\hline & $\begin{array}{l}\text { FES no ha respetado el } \\
\text { Dictamen Ético del } \\
\text { CONAR incurriendo en } \\
\text { actos y omisiones arbitra- } \\
\text { rias e ilegales (Fundación } \\
\text { Instituto de la Mujer, } \\
\text { 2005). }\end{array}$ & & $\begin{array}{l}\text { "En este caso se trataba de } \\
\text { una historia irreal [...]" } \\
\text { (Konitzki, 2005 en Lechu- } \\
\text { ga, 2005, p. 7). }\end{array}$ \\
\hline & $\begin{array}{l}\text { Actriz } 1 \text { (¿) } \\
\text { "[...] la propia tienda tie- } \\
\text { ne un marketing que lla- } \\
\text { ma a la violencia, espe- } \\
\text { cialmente la juvenil" } \\
\text { (Ballara, 2005 en } \\
\text { CONAR, 2005, p. 2). }\end{array}$ & $\begin{array}{l}\text { "[...] se está generando en } \\
\text { nuestra sociedad una toma } \\
\text { de conciencia sobre la vio- } \\
\text { lencia y el maltrato a las } \\
\text { personas, especialmente } \\
\text { el que se produce al inte- } \\
\text { rior de algunas familias } \\
\text { afectando a mujeres y ni- } \\
\text { ños [...] si bien la publici- } \\
\text { dad no está obligada a } \\
\text { cumplir un rol educativo, } \\
\text { tampoco debería utilizar } \\
\text { imágenes o situaciones de } \\
\text { extrema violencia que } \\
\text { dramaticen estos hechos } \\
\text { fuera de contexto" } \\
\text { (CONAR, 2005, p. 5). }\end{array}$ & $\begin{array}{l}\text { El contenido irreal de la } \\
\text { publicidad está debida- } \\
\text { mente contextualizado } \\
\text { como parodia de películas } \\
\text { como Pulp Fiction, Kill } \\
\text { Bill y/o Contracara } \\
\text { (Konitzki, 2005 en } \\
\text { CONAR, 2005). } \\
\text { La trama ficticia del aviso } \\
\text { publicitario no puede } \\
\text { transformarse en hechos de } \\
\text { la realidad como equivoca- } \\
\text { damente atribuyen las de- } \\
\text { nunciantes (Konitzki, } \\
2005 \text { en CONAR, 2005). }\end{array}$ \\
\hline & $\begin{array}{l}\text { "Nos parece peligroso un } \\
\text { camino de tolerancia con } \\
\text { una publicidad que pre- } \\
\text { tendiera hacer uso de la } \\
\text { violencia como recurso } \\
\text { publicitario, justamente } \\
\text { para provocar mayor im- } \\
\text { pacto en la audiencia, } \\
\text { pues la posible legitimi- } \\
\text { dad de un fin económico } \\
\text { o comercial no puede } \\
\text { lograrse por vías aparta- } \\
\text { das de la ética y los dere- } \\
\text { chos fundamentales" } \\
\text { (Fundación Instituto de la } \\
\text { Mujer, 2005, p. 4). }\end{array}$ & & $\begin{array}{l}\text { El CONAR, como no es } \\
\text { una entidad legal, su Dic- } \\
\text { tamen Ético no es obliga- } \\
\text { torio acatarlo (Konitzki, } \\
2005 \text { en Lechuga, 2005). }\end{array}$ \\
\hline
\end{tabular}




\begin{tabular}{|l|l|l|l|}
\hline Atribución & $\begin{array}{l}\text { Llamamiento a la violen- } \\
\text { cia (Ballara, 2005 en } \\
\text { CONAR, 2005). } \\
\text { Vulneración del Código } \\
\text { Chileno de Ética Publici- } \\
\text { taria, Art. 3 (Fundación } \\
\text { taria, Art. 3. }\end{array}$ & $\begin{array}{l}\text { Instituto de la Mujer, 2005 } \\
\text { en CONAR, 2005). } \\
\text { Incumplimiento del Dicta- } \\
\text { men Ético elaborado por el } \\
\text { CONAR (Fundación Ins- } \\
\text { tituto de la Mujer, 2005). }\end{array}$ & $\begin{array}{l}\text { Entendimiento errado de } \\
\text { las denunciantes. }\end{array}$ \\
\hline
\end{tabular}

Descripción para la Matriz III:

\section{Fuentes del Poder}

En el primer momento del conflicto la $D i$ versificación de Relaciones utilizada por la Actriz 1 y 2 es buscar apoyo a la denuncia contra FES en el CONAR. Este último Actor acoge la denuncia interpuesta mediante la emisión del Dictamen Ético, el cual es rechazado por el Actor 4, FES. Antes esto, la Fundación Instituto de la Mujer busca protección a los derechos vulnerados en la Corte de Apelaciones de Santiago, lo cual abre el segundo momento del conflicto.

Para la Actriz 1 y 2 los Recursos Pertinentes en la primera fase del conflicto es la denuncia ante el CONAR. Este último dispone del Dictamen Ético. Sin embargo como este adolece del carácter coercitivo y obligatorio de la Constitución y las leyes, FES decide la mantención de la publicidad. En el segundo momento del conflicto, los Recursos Pertinentes para la Fundación Instituto de la Mujer son de índole financiera para contratar un abogado especialista en ética publicitaria (Lechuga, 2005) que presente un Recurso de Protección ante la Corte de Apelaciones de Santiago. Respecto de FES, en tanto no ha realizado sus descargos ante el Tribunal mediante un abogado representante no puede inferirse que posee recursos financieros para tal acción.

En el primer momento del conflicto todos los actores involucrados se basan en el Código Chileno de Ética Publicitaria, que a través de su Art. $3^{\circ}$ señala textualmente: "Los mensajes no deben inducir a realizar o apoyar actos de violencia en ninguna de sus manifestaciones". Respecto de la interpretación del mencionado Art. las Actrices 1 y 2 y el Actor estiman que la publicidad de FES vulnera el texto expreso recién trascrito. Por su parte FES opina lo contrario.
En el segundo momento del conflicto ante los derechos vulnerados por FES al no acatar el dictamen ético del CONAR, la Fundación Instituto de la Mujer presenta un Recurso de Protección amparado en la Constitución Política de la República de Chile [CPE]: Art. 19 $N^{\circ} 1$, Derecho a la Vida y a la Integridad Física y Psíquica de la Persona; $19 \mathrm{~N}^{\circ} 2$, la Igualdad Ante la Ley y el deber de no discriminación; Art. $19 \mathrm{~N}^{\circ} 4$, Respeto y Protección a la vida privada y pública y a la honra de la persona y su familia; Art. $19 \mathrm{~N}^{\circ} 12$, la Libertad de Expresión; Art. 13 de la Convención Americana de Derechos Humanos; $19 \mathrm{~N}^{\circ} 21$, Derecho a desarrollar cualquier actividad económica teniendo la moral como límite. La Convención para la Eliminación de todas las Formas de Discriminación contra la Mujer; ratificada por Chile en 1989, Art. 2, letra e y aplicable en virtud del Art. 5, inc. 2 [CPE]; la Convención Interamericana para Prevenir; Sancionar y Erradicar la Violencia contra la Mujer; Art. 1 y 8, g; Convención de los Derechos del Niño, Art. 3 sobre el Interés superior del Niño (Fundación Instituto de la Mujer, 2005).

El Tiempo Disponible para la Actriz 1 y 2 en el primer momento del conflicto es Menor porque al presentar la denuncia ante el CONAR este demoró 12 días en emitir el Dictamen Ético (CONAR, 2005, p. 1). Durante ese lapso la publicidad continuó exhibiéndose, siendo esto último lo que se busca rechazar, idealmente, con un dictamen emitido más prontamente. Para FES el Tiempo Disponible es Mavor porque al esperar el Dictamen Ético del CONAR sigue exhibiéndose la publicidad, siendo esto último lo que se busca. En la segunda fase del conflicto el Tiempo Disponible para la Fundación Instituto de la Mujer es Aín Menor porque la campaña 


\section{CRISTIÁN VENEGAS}

publicitaria de FES está proyectada con un margen temporal acotado, que puede cumplirse antes de obtener el fallo por parte de la Corte de Apelaciones de Santiago. En este sentido, no existe un margen temporal claramente establecido para que el Tribunal conozca la causa y dicte sentencia. Esto último le otorga un Tiempo Disponible Aún Mayor a FES para que su publicidad continúe exhibiéndose.
En el conflicto, la Mujer padece una Victimización Colectiva Primaria producto del Contenido de un Anuncio Publicitario que viola sus derechos. Además al recurrir al Sistema Judicial se produce una Victimización Colectiva Secundaria, pues es el propio sistema que en la tardanza en ver la causa y dictar sentencia, profundiza (sin proponérselo conscientemente) el abuso y violación de los derechos de la Mujer.

Matriz III: Fuentes del Poder

\begin{tabular}{|c|c|c|c|}
\hline & $\begin{array}{l}\text { Actriz } 1 \text { / Actriz } 2 \\
\text { Marcela Ballara } \\
\text { Fundación Instituto } \\
\text { de la Mujer }\end{array}$ & $\begin{array}{l}\text { Actor } 3 \\
\text { CONAR }\end{array}$ & $\begin{array}{c}\text { Actor } 4 \\
\text { FES }\end{array}$ \\
\hline \multirow[t]{2}{*}{$\begin{array}{l}\text { Diversificación de } \\
\text { Relaciones }\end{array}$} & $\begin{array}{l}\text { Buscar apoyo a la denun- } \\
\text { cia contra FES en el } \\
\text { CONAR. }\end{array}$ & $\begin{array}{l}\text { Acoger la Denuncia inter- } \\
\text { puesta por Marcela } \\
\text { Ballara y FES. }\end{array}$ & $\begin{array}{l}\text { Rechazar el Dictamen Éti- } \\
\text { co del CONAR. }\end{array}$ \\
\hline & $\begin{array}{l}\text { Buscar protección en Tri- } \\
\text { bunales y presentación del } \\
\text { caso o sus antecedentes } \\
\text { ante Organismos Interna- } \\
\text { cionales, Comisiones de } \\
\text { Derechos Humanos u Ór- } \\
\text { ganos del Sistema de Na- } \\
\text { ciones Unidas (Fundación } \\
\text { Instituto de la Mujer, } \\
\text { 2005). }\end{array}$ & & $i$ \\
\hline \multirow[t]{2}{*}{ Recursos Pertinentes } & $\begin{array}{l}\text { Denuncia ante el } \\
\text { CONAR. }\end{array}$ & Dictamen Ético. & $\begin{array}{l}\text { Mantención de la publici- } \\
\text { dad. }\end{array}$ \\
\hline & $\begin{array}{l}\text { Recursos Económicos } \\
\text { para contratar un abogado } \\
\text { especialista en ética publi- } \\
\text { citaria. } \\
\text { Contacto con red de Orga- } \\
\text { nismos de la Mujer. } \\
\text { Recurso de Protección in- } \\
\text { terpuesto en la Corte de } \\
\text { Apelaciones de Santiago. }\end{array}$ & & \\
\hline \multirow[t]{2}{*}{ (Código) / Leyes } & $\begin{array}{l}\text { Código Chileno de Ética } \\
\text { Publicitaria, Art. } \mathrm{N}^{\circ} 3 \text {. }\end{array}$ & $\begin{array}{l}\text { Código Chileno de Ética } \\
\text { Publicitaria, Art. } N^{\circ} 3 \text {. }\end{array}$ & $\begin{array}{l}\text { Código Chileno de Ética } \\
\text { Publicitaria, Art. } \mathrm{N}^{\circ} 3 \text {. }\end{array}$ \\
\hline & $\begin{array}{l}{[\mathrm{CPE}]:} \\
\text { Art. } 19 \mathrm{~N}^{\circ} 1 \text { Derecho a la } \\
\text { Vida y a la Integridad Fí- } \\
\text { sica y Psíquica de la Per- } \\
\text { sona, } 19 \mathrm{~N}^{\circ} 2 \text {, la Igualdad } \\
\text { Ante la Ley y el deber de } \\
\text { no discriminación, Art. } 19 \\
\mathrm{~N}^{\circ} 4 \text { Respeto y Protección } \\
\text { a la vida privada y públi- } \\
\text { ca y a la honra de la per- } \\
\text { sona y su familia, Art. } 19\end{array}$ & & \\
\hline
\end{tabular}




\begin{tabular}{|c|c|c|}
\hline & $\begin{array}{l}\mathrm{N}^{\circ} 12, \text { la Libertad de Ex- } \\
\text { presión, Art. } 13 \text { de la Con- } \\
\text { vención Americana de } \\
\text { Derechos Humanos, } 19 \\
\mathrm{~N}^{\circ} 21 \text {, Derecho a desarro- } \\
\text { llar cualquier actividad } \\
\text { económica teniendo la } \\
\text { moral como límite. La } \\
\text { Convención para la Eli- } \\
\text { minación de todas las } \\
\text { Formas de Discrimina- } \\
\text { ción contra la Mujer; rati- } \\
\text { ficada por Chile en } 1989 \text {, } \\
\text { Art. } 2 \text {, letra e y aplicable } \\
\text { en virtud del Art. } 5 \text {, inc. } 2 \\
\text { [CPE]; la Convención In- } \\
\text { teramericana para Preve- } \\
\text { nir; Sancionary Erradicar } \\
\text { la Violencia contra la } \\
\text { Mujer; Art. } 1 \text { y } 8 \text {, g; Con- } \\
\text { vención de los Derechos } \\
\text { del Niño, Art. } 3 \text { sobre el } \\
\text { Interés superior del Niño } \\
\text { (Fundación Instituto dẹ la } \\
\text { Mujer, 2005). }\end{array}$ & \\
\hline \multirow[t]{2}{*}{ Tiempo Disponible } & $\begin{array}{l}\text { Menor: Porque al esperar } \\
\text { el Dictamen Ético del } \\
\text { CONAR sigue exhibién- } \\
\text { dose la publicidad. Bus- } \\
\text { cando rechazar esto últi- } \\
\text { mo. }\end{array}$ & $\begin{array}{l}\text { Mayor: Porque al esperar } \\
\text { el Dictamen Ético del } \\
\text { CONAR sigue exhibién- } \\
\text { dose la publicidad. Bus- } \\
\text { cándose esto último. }\end{array}$ \\
\hline & $\begin{array}{l}\text { Aún Menor: Porque, la } \\
\text { campaña publicitaria de } \\
\text { FES está proyectada con } \\
\text { un margen temporal aco- } \\
\text { tado, que puede cumplir- } \\
\text { se antes de obtener el fa- } \\
\text { llo por parte de la Corte de } \\
\text { Apelaciones de Santiago. }\end{array}$ & $\begin{array}{l}\text { Aún Mayor: Porque la } \\
\text { Corte de Apelaciones de } \\
\text { Santiago, se demora para } \\
\text { llegar a resolver median- } \\
\text { te el fallo, dando espacio } \\
\text { a que la publicidad siga } \\
\text { exhibiéndose. }\end{array}$ \\
\hline
\end{tabular}

\section{Descripción para la Matriz IV: Estrategias.}

En relación con las Estrategias utilizadas en la primera parte del conflicto, la Actriz 1 y 2 denuncian el caso al CONAR, quien realiza el Dictamen Ético no acatado por FES. Esta última maniobra es permitida por un encuadre legal que no otorga el carácter obligatorio y coercitivo al Dictamen del CONAR. Con esta estrategia se gana tiempo para mantener la publicidad exhibiéndose. En el segundo momento del conflicto la Fundación Instituto de la Mujer opta por Judicializar el Caso mediante la presentación de un Recurso de Protección interpuesto en la Corte de Apelaciones de Santiago, buscando con ello la obligatoriedad y coercitividad de un fallo emitido por el Tribunal. A esto se suma el Aumento de Poder mediante el cual la Fundación Instituto de la Mujer busca la presentación del caso o sus antecedentes ante Organismos Internacionales, Comisiones de Derechos Humanos u Órganos del Sistema de Naciones Unidas (Fundación Instituto de la Mujer, 2005). Por su parte, y de modo extrajudicial FES lo que hace es Bajarle el Perfil al Caso atribuyendo el conflicto a un error de entendimiento de las denunciantes en un primer momento y luego a un carácter y perfil intrínsecamente polémico de las campañas publicitarias de FES en el pasado y en el presente caso, por tanto no sería algo preocupante. 
El conflicto analizado ha sido reporteado por medios de Comunicación Masiva tanto prensa escrita (incluidos periódicos en Internet) como en Canales de Televisión. No ha podido establecerse hasta ahora si la noticia ha sido cubierta por los periodistas motivados por una alerta entregada por algún actor del conflicto. Si esto último hubiera sido así, "Hacer Público el Con- flicto" es una Estrategia que como siempre, tiene un aspecto dual, por una parte ayuda a crear conciencia sobre el problema y permite eventualmente la suma de apoyo a la Fundación Instituto de la Mujer, pero también es una ayuda a FES porque su publicidad se extiende a más público siendo ese el objetivo de toda publicidad.

Matriz IV: Estrategias

\begin{tabular}{|l|l|l|l|}
\hline & \multicolumn{1}{|c|}{$\begin{array}{c}\text { Actriz 1 / Actriz 2 } \\
\text { Marcela Ballara } \\
\text { Fundación Instituto } \\
\text { de la Mujer }\end{array}$} & $\begin{array}{c}\text { Actor 3 } \\
\text { CONAR }\end{array}$ & \multicolumn{1}{c|}{$\begin{array}{c}\text { Actor 4 } \\
\text { FES }\end{array}$} \\
\hline Estrategias & $\begin{array}{l}\text { Denunciar el Caso al } \\
\text { CONAR. }\end{array}$ & $\begin{array}{l}\text { Realizar el Dictamen Éti- } \\
\text { co. }\end{array}$ & $\begin{array}{l}\text { No Acatar el Dictamen } \\
\text { Ético del CONAR. }\end{array}$ \\
\cline { 2 - 4 } & $\begin{array}{l}\text { Judicializar el Caso } \\
\text { Aumento de Poder }\end{array}$ & Bajarle el Perfil al Caso. \\
\hline
\end{tabular}

\section{Conclusiones y Discusión}

$\mathrm{El}$ análisis del conflicto psicosocial jurídico entre la Fundación Instituto de la Mujer y la tienda FES ha permitido situar los discursos de las partes en Condiciones de Producción (cultura patriarcal, muerte de mujeres víctimas de violencia, la Constitución, las leyes y Convenciones que protegen a la Mujer) y sus Condiciones de Reconocimiento (Recurso de Protección). En este contexto las actrices Marcela Ballara y la Fundación Instituto de la Mujer al recurrir al CONAR, existe una toma de conciencia sobre la muerte de Mujeres por violencia intrafamiliar (condición social) y respecto de la violencia contra la Mujer presente en el anuncio publicitario de FES, como un atentado contra valores como el respeto y la dignidad de la Mujer (problema social).

Existe un conflicto respecto de la interpretación del Art. $3^{\circ}$ del Código Chileno de Ética Publicitaria donde el discurso de FES puede entenderse dentro de la Cultura Patriarcal: Niega lo diferente, no acepta que exista una interpretación distinta del Objeto: Contenido del Anuncio Publicitario; No acata el Dictamen del CONAR, porque no es coercitivo, lo que en una cultura basada en el Control y la Autoridad no tiene peso. Así Fundación Instituto de la Mujer debe seguir el camino judicial para entrar en el universo simbólico del Patriarcado con su modelo de orden impuesto para la resolución de conflictos, así se busca hacer valer los derechos vulnerados.

En el conflicto, la Mujer padece una Victimización Colectiva Primaria producto del Contenido del Anuncio Publicitario que viola sus derechos. Además al recurrir al Sistema Judicial se produce una Victimización Colectiva Secundaria, pues el propio sistema en la tardanza para ver la causa y dictar sentencia, profundiza el abuso y violación de los derechos de la Mujer.

La perspectiva teórica de género y el ACD han visibilizado en los Discursos sus Condiciones de Producción y Reconocimiento, mediante la desarticulación del discurso como estrategia tendiente a mostrar el conflicto psicosocial jurídico desde una visión que problematiza la violencia que victimiza a la mujer y también al hombre; porque en una cultura patriarcal convivir en paz y justicia es siempre una invitación para todos /as.

\section{Referencias.}

Allen, C., O' Guinn, T., Semenik, R. (1998). Glosario. En: Publicidad (pp. 577-588). México: International Thomson, 1999.

Andueza, P. (1997). Orden impuesto y orden negociado en el campo de resolución de conflictos jurídicos. Estudios Sociales 92, 157-172.

Andueza, P. (2004a, Abril). La mediación en el contexto juridico y social chileno / Teorias del conflicto. Cátedra Electiva de Mediación (III Semestre). Magíster en Psi- 
cología Social Mención en Psicología Jurídica, Escuela de Psicología, Universidad de Valparaíso, Chile.

Andueza, P. (2004b). Mamual para el curso Sistemas Socio-Técnicos [Documento no publicado]. Curso de Sistemas Socio-Técnicos (III Semestre). Carrera de Licenciatura en Ciencias Socio-Económicas, Universidad de Valparaíso, Chilc.

Andueza, P. (2004c, Julio). Area de Aplicación: Mediación Social. Cátedra Electiva de Mediación (III Semestre). Magíster en Psicología Social Mención en Psicología Jurídica, Escuela de Psicología, Universidad de Valparaíso, Chile.

Bourdicu, P. (1985). La formación de precios y la previsión de beneficios. En: ¿Qué significa hablar? Economia de los intercambios lingï̈sticos (pp. 40-62). Madrid: AKAL / Universitaria, 1985.

Bourdicu, P. (1986). La force du droit. Eléments pour unc sociologie du champ juridique. Actes de la recherche en sciences sociales, $\mathrm{N}^{\circ} 64$ (Andueza, P., Trad.).

Bourdieu, P. (1997). ¿Es posible un acto desinteresado? En: Razones prácticas. Sobre la teoría de la acción (pp. 139158). Barcelona: Anagrama, 1997.

Carnelutti, F. (1944a). Sistema de Derecho Procesal Civil. (Tomo I). Buenos Aires: Uthea.

Carnclutti, F. (1944b). Sistema de Derecho Procesal Civil. (Tomo II). Bucnos Aires: Uthea.

Castellón, J. (2004). Diccionario de derecho procesal civil. Santiago: Editorial Jurídica La Ley, 2004.

Clemente, M. (1992). Los problemas sociales: Qué son y cómo se manifiestan. En: Psicología Social Aplicada (pp. 1I- 28). Madrid: Pirámide, 1997.

Código Civil de Chile (1999). (13 $3^{\mathrm{a}} \mathrm{ed}$.). Santiago: Editorial Jurídica de Chile, 1999.

Colaizzi, G. (1990). Feminismo y teoría del discurso: razones para un debate. En: Colaizzi, G. (Ed). Feminismo y teoría del discurso (pp. 13-25). Barcelona: Cátedra, 1990.

Conscjo Nacional de Autorregulación y Ética Publicitaria (2005, Abril). Fallo [No publicado].

Crozier, M. \& Friedberg, E. (1977). L acteur et le système. Paris: Seuil.

Chávez, G. (2006). Victimología y Policia. Extraido el 27 de febrero del 2006, de http://www.psicologiajuridica.org/ psi37.html

De Quiroga, A. (2002). Las relaciones entre proceso psicosocial y la subjetividad hoy. En: Asún, D., Lía, A., Morales, J., Páez, D. (Coords.). Psicología Social (pp. 1-14). Buenos Aires: Prentice Hall, 2002.

Demicheli, G. (2004, mayo). Los procesos psicológicos. Cátedra Electiva de Mediación (III Scmestre). Magíster en Psicología Social Mención en Psicología Jurídica, Escucla de Psicología, Universidad de Valparaíso, Chile.

Díaz, F. (2006). Perspectiva victimológica en la solución de conflictos sociales. Artículos de Victimología. Extraido el $27 \mathrm{del}$ febrero del 2006, de http:// www.psicologiajuridica.org/

Eisler, R. (1987). Un avance en la cvolución: Hacia un futuro solidario. En: El cáliz y la espada. Nuestro pasado, muestro futuro (pp. 210-231). Santiago: Cuatro Vientos, 1993.

Ferrater, J. (1965). Diccionario de Filosofía (5a ed.). Bucnos Aires: Sudamericana.
FES (2005). FES fiee. [Foto Publicitaria]. Extraída el 5 de Octubre del 2005, de www. fesjeans.com

Fundación Instituto de la Mujer (2005, Mayo). Recurso de Protección [No publicado].

Galván, M. (2003). Psicología Social Jurídica, Derecho Penal y Representaciones sociales. Aproximaciones al estatus epistemológico de la Psicología Social Juridica. En: Anales V Congreso Iberoamericano de Psicología Juridica (pp. 47-62). Santiago: Asociación Iberoamericana de Psicología Jurídica \& Policía de Investigaciones de Chile.

Garcia-Borés, J. (1996). La desarticulación de discursos y la "versión única" como fenómeno c instrumento de poder. En: Gordo, A \& Linaza, J. (Compls.). (1996). Psicologías, discursos y Poder (PDP) (pp. 339-351). Madrid: Visor, 1996.

Geertz, C. (1973). La descripción densa. En: La interpretación de las culturas (pp. 9-40). Barcelona: Gedisa, 2001.

Hoyos, F. (1987). Temas fundamentales de Derecho Procesal. Santiago: Editorial Jurídica de Chile, 1987.

Huberman, A. \& Miles, M. (1992). Analyse des données qualitatives. Recueil de nouvelles méthodes. Bclgium: De Boeck-Wesmael.

Íñiguez, L. (Ed.). (2003). Análisis del discurso. Manual para las Ciencias Sociales. Barcelona: UOC, 2003.

Jenikins, R. (1992). Practice, Habitus and Field. En: Pierre Bourdieu (pp. 66-102). London: Routledglc, 1992.

Lechuga, L. (2005, mayo 19). Recurso judicial contra sangriento aviso. Las Últimas Noticias, p. 7.

Leibniz, G. (1984). Escritos de Filosofia juridica y política. Madrid: Nacional.

Maturana, H. (1993). Conversaciones matrísticas y patriarcales. En: Maturana, H. \& Verden-Zöller, G. Amor y juego. Fundamentos olvidados de lo humano desde el Patriarcado a la Democracia (pp. 19- 69). Santiago: Instituto de Terapia Cognitiva, 1997.

Max-Neef, M. Elizalde, A. \& Hopenhayn, M. (1986). Desarrollo a escala humana. Una opción para el futuro. Santiago: CEPAUR-Fundación Dag Hammarskjold.

Moya, M. (1994). Percepción Social y de personas. En: Morales, J. (coord.). Psicología social (pp. 93-122). Madrid: McGraw-Hill / Interamericana de España.

Myers, D. (1995). Psicología Social (4a ed.). México: McGraw-Hill, 1995.

Orgaz, A. (1961). Diccionario de derecho y Ciencias Sociales. Córdoba: Assandi.

Quijada, R. (1994). Diccionario jurídico. Santiago: Juridica Cono Sur

Ricceur, P. (1986). Del terto a la acción. Ensavos de Hermenéutica II. Buenos Aires: Fondo de Cultura Económica, 2001

Rocco, U. (1969). Tratado de derecho procesal Civil (Vol. I). Buenos Aires: Depalma.

Rodríguez, D. (1995). Conflicto. En: Gestión organizacional: Elementos para su estudio (pp. 105-122). (2 ed.). Santiago: Procop.

Scrvicio Nacional de la Mujer (2006). Género. En: Glosario de conceptos de violencia. Extraido el 23 de febrero del 2006, de, http://www.sernam.cl/basemujer/index.htm

Vander, J. (1994). Manual de Psicologia Social (2 ${ }^{\mathrm{a}}$ ed.). Barcelona: Paidós Ibćrica. 


\section{CRISTIÁN VENEGAS}

Van Dijk, T. (1987). Objetivos del análisis crítico de discurso. En: Racismo y análisis critico de los medios (pp. 1526). Barcelona: Paidós, 1997.

Van Dijk, T. (2001a). (comp.). El discurso como estructura y proceso (Vol. I). Barcelona: Gedisa.

Van Dijk, T. (2001b). (comp.). El discurso como interacción social(Vol. II). Barcclona: Gedisa.
Venegas, C. (2006). La modernización de la justicia en Chile en el Discurso de Inauguración del Año Judicial 1994 y en un Discurso Oficial del Ministerio de Justicia, 1994. Ponencia presentada en el $3^{\circ}$ Congreso Virtual Latinoamericano de Psicología Jurídica y Forense (3-5 de abril). Realizado en, www.psicologiajuridica.org/

Verón, E. (1987). La semiosis social. Fragmentos de una teoría de la discursividad. Barcelona: Gedisa, 1987.

Anexo: Ejemplo de Anuncio Publicitario de Fes (2005)

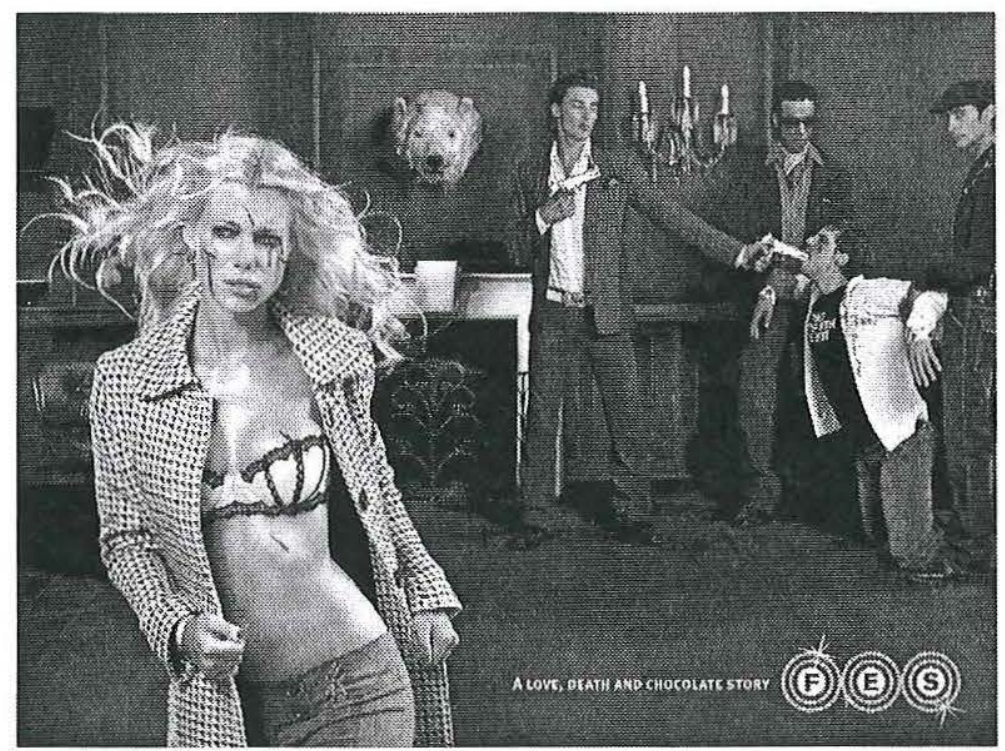

